University of Wollongong

Research Online

Australian Institute for Innovative Materials -

Papers

Australian Institute for Innovative Materials

$1-1-2020$

Electrical stimulation-induced osteogenesis of human adipose derived stem cells using a conductive graphene-cellulose scaffold

Jianfeng Li

University of Wollongong, j1677@uowmail.edu.au

Xiao Liu

University of Wollongong, xiaol@uow.edu.au

Jeremy Micah Crook

University of Wollongong, University of Melbourne, jcrook@uow.edu.au

Gordon G. Wallace

University of Wollongong, gwallace@uow.edu.au

Follow this and additional works at: https://ro.uow.edu.au/aiimpapers

Part of the Engineering Commons, and the Physical Sciences and Mathematics Commons

Research Online is the open access institutional repository for the University of Wollongong. For further information contact the UOW Library: research-pubs@uow.edu.au 


\title{
Electrical stimulation-induced osteogenesis of human adipose derived stem cells using a conductive graphene-cellulose scaffold
}

\author{
Abstract \\ The versatile properties of graphene-based materials are enabling various tissue regeneration, towards \\ meeting an ever increasing demand for replacement tissues due to injury through trauma and disease. In \\ particular, an innate ability for graphene to promote osteogenic differentiation of stem cells, combined \\ with the potential to enhance the biological activity of cells through electrical stimulation (ES) using \\ graphene, supports its use for osteoinduction or reconstruction. In this paper, we describe a miniaturized \\ graphene-cellulose (G-C) scaffold-based device that incorporates electroactive G-C 'paper' within a \\ polystyrene chamber for concomitant cell culture and ES. The G-C electrodes possessed lower \\ impedance and higher charge injection capacity than gold ( $\mathrm{Au}$ ) electrodes, with high stability. By coupling \\ ES with previously reported properties of the G-C scaffolds, we have advanced the platform for improved \\ adipose derived stem cell (ADSC) support and osteogenic differentiation. We anticipate using the G-C \\ scaffold-based ES device for in vitro modelling of osteogenic induction, bone tissue engineering and in \\ vivo bone regeneration towards new therapeutic strategies for bone injury and disease. Furthermore, the \\ device could reasonably be used for ES and culture of other cell types and engineering other tissues.

\section{Disciplines} \\ Engineering | Physical Sciences and Mathematics

\section{Publication Details} \\ Li, J., Liu, X., Crook, J. M. \& Wallace, G. G. (2020). Electrical stimulation-induced osteogenesis of human \\ adipose derived stem cells using a conductive graphene-cellulose scaffold. Materials Science and \\ Engineering C: Materials for Biological Applications, 107 110312-1-110312-9.
}


1 Electrical stimulation-induced osteogenesis of human adipose derived stem cells using a

2 conductive graphene-cellulose scaffold

3 Jianfeng Lit ${ }^{1}$ Xiao Liu ${ }^{1 *}$, Jeremy M. Crook ${ }^{1,2,3 *}$, and Gordon G. Wallace $e^{1 *}$

$4 \quad{ }^{1}$ ARC Centre of Excellence for Electromaterials Science,

5 Intelligent Polymer Research Institute, AIIM Facility,

$6 \quad$ University of Wollongong, NSW 2500, Australia

7 2Illawarra Health and Medical Research Institute, University of Wollongong, Wollongong,

8 New South Wales 2522, Australia

$9{ }^{3}$ Department of Surgery, St Vincent's Hospital, The University of Melbourne, Fitzroy,

10 Victoria 3065, Australia

11 Abstract

12

The versatile properties of graphene-based materials are enabling various tissue regeneration, towards meeting an ever increasing demand for replacement tissues due to injury through trauma and disease. In particular, an innate ability for graphene to promote osteogenic differentiation of stem cells, combined with the potential to enhance the biological activity of cells through electrical stimulation (ES) using graphene, supports its use for osteoinduction or reconstruction. In this paper, we describe a miniaturized graphene-cellulose (G-C) scaffoldbased device that incorporates electroactive G-C 'paper' within a polystyrene chamber for concomitant cell culture and ES. The G-C electrodes possessed lower impedance and higher charge injection capacity than gold ( $\mathrm{Au}$ ) electrodes, with high stability. By coupling ES with previously reported properties of the G-C scaffolds, we have advanced the platform for improved adipose derived stem cell (ADSC) support and osteogenic differentiation. We anticipate using the G-C scaffold-based ES device for in vitro modelling of osteogenic induction, bone tissue engineering and in vivo bone regeneration towards new therapeutic strategies for bone injury and disease. Furthermore, the device could reasonably be used for ES and culture of other cell types and engineering other tissues.

*Corresponding authors E-mail addresses: jcrook@uow.edu.au; gwallace@uow.edu.au; xiaol@uow.edu.au 


\section{Introduction}

An increasing demand for bone implants worldwide due, in part, to rising life expectancy is driving the development of bone tissue engineering approaches to treat injury from trauma and disease. Human adipose stem cells (ADSCs) offer significant potential for bone tissue engineering since they are easy to source as self-renewing cells that can be expanded to large cell numbers ex vivo. They also undergo osteogenic differentiation and can be used for autologous therapy [1,2]. Graphene, as an important carbon nanomaterial, is distinguished by its superior performance for a variety of biomedical applications, including human tissue/organ regeneration [3]. In particularly, graphene based materials have attracted considerable interest for osteo-induction or reconstruction due to an innate ability to promote (without additional inducers) osteogenic differentiation of several stem cell types, including ADSCs [4]. As reported by others, the underlying mechanisms of graphene-enhanced stem cell osteogenesis involves activation of physiologically-relevant mechanotransduction pathways by graphene and facilitation of cell anchorage by the mechanical in-plane stiffness and topographical features of graphene $[5,6]$. Additionally, graphene has high electrical conductivity and therefore the potential to be used for electrically stimulating cells and tissues in vitro or in vivo. Electrical stimulation (ES) has been shown to promote migration, proliferation and differentiation of stem cells, including neural stem cells, bone marrow stromal cells, and ADSCs through modulation of intracellular signalling [7-12]. Previous studies have shown that intracellular calcium/calmodulin pathway, downstream calcineurin/NFAT signalling pathway, and master osteogenic transcription factor runt-related transcription factor 2 can be activated by ES, resulting in enhanced osteogenic differentiation of stem cells [1315]. Notwithstanding the putative benefits of ES, there is a need for advanced biocompatible ES devices that omit the use of conventional electrodes such as metal electrodes for more optimal cell-compatibility, avoiding, for example, unwanted biochemical effects of corrosion and poor physical integration with cells and tissues [7].

We and others have shown that graphene-based materials are capable of supporting and enhancing stem cell growth and differentiation towards osteogenic lineage [16-19]. Most recently, we have reported the development of graphene-cellulose (G-C) 'paper' for 3D human ADSC support and osteoinduction [20]. The G-C paper is electrically conductive, has an intricate 3D architecture, is robust, flexible, cytocompatible, easy-to-fabricate and amenable for large-scale production [20], and is therefore advantageous over other graphene-based 
scaffolds $[17,21,22]$. Here we describe the use of our G-C paper to develop a device for augmented osteogenic differentiation by ES of ADSCs. Briefly, the G-C paper was applied as a cell supporting electroactive scaffold for externally applied ES using an electrical stimulator. We have shown that the G-C scaffold electrode is stable and can achieve lower impedance and higher charge injection capacity than an Au electrode. ADSCs can be maintained on the scaffold with externally applied ES augmenting stem cell proliferation and osteogenic differentiation. The platform is both scalable and potentially adaptable to a variety of other cells and tissues, for use in basic research through to clinical-grade tissue development.

\section{Experimental section}

\subsection{Materials}

G-C scaffolds were prepared using previously described materials [20]. In addition, for the present studies, Nunc ${ }^{\circledR}$ Lab-Tek ${ }^{\circledR}$ II chambered coverglass (polystyrene), L-ascorbic acid2-phosphate, dexamethasone and $\beta$-glycerophosphate were purchased from Sigma-Aldrich (USA). Au coated Mylar was purchased from Solutia Performance Films and clear RTV silicone adhesive sealant was purchased from Permatex (USA). Copper tape with adhesive backing was purchased from ProSciTech (Australia) and human ADSCs were obtained from Lonza Corporation (Australia). Gibco Dulbecco's Modified Eagle Medium (DMEM), nonessential amino acids (NEAA) solution, foetal bovine serum (FBS), penicillin, streptomycin, basic fibroblast growth factor (bFGF), calcein AM, propidium iodide (PI) and PrestoBlue ${ }^{\circledR}$ were obtained from Thermo Fisher (Australia). Methanol and acetic acid were purchased from Chem-Supply (Australia).

\subsection{Preparation of G-C scaffolds}

An aqueous graphene oxide (GO) suspension $(4.5 \mathrm{mg} / \mathrm{ml})$ was synthesized by modified Hummers method and used for G-C scaffold fabrication [20, 23]. G-C scaffolds were prepared according to previously described method [20]. Briefly, cellulose tissue paper (KimberlyClark, Australia) was laser cut (ULS PLS6MWLaser Engraver) to $1.5 \mathrm{~cm} \times 3 \mathrm{~cm}$ size, deposited with $45 \mu \mathrm{l}$ of $4.5 \mathrm{mg} / \mathrm{ml} \mathrm{GO}$ aqueous dispersion, and dried at $100{ }^{\circ} \mathrm{C}$ for $2 \mathrm{~min}$ using 
1 a hotplate. The GO coating and drying was repeated $3 \times$ followed by reduction in $50 \mathrm{mM} \mathrm{L-}$ ascorbic acid solution at $80{ }^{\circ} \mathrm{C}$ for $3 \mathrm{~h}$ and drying again at $100{ }^{\circ} \mathrm{C}$ on a hotplate [24].

\subsection{Assembly of ES device}

5

6

The fabricated G-C scaffolds were assembled into an ES device as illustrated in Fig. 1. Strips of G-C scaffolds $(3 \mathrm{~cm} \times 0.5 \mathrm{~cm})$ were mounted in parallel onto a glass slide (Sail Brand, China), and a polystyrene chamber $\left(0.7 \mathrm{~cm}^{2} /\right.$ well; with an open bottom and top, and removable lid) was carefully positioned on top and fixed into position overnight using silicon adhesive sealant. Copper tapes with adhesive backing were then adhered to both sides of the glass slide so as to contact the G-C scaffold strips, while extending beyond the polystyrene chamber. The assembled device was immersed in $70 \%$ ethanol solution for $3 \mathrm{~h}$, UV irradiated for $2 \times 20$ min and dried for $10 \mathrm{~h}$ in a laminar flow cabinet. The device was then connected to an electrical stimulator using copper wires (Diameter: $2 \mathrm{~mm}$ ).

\subsection{Scanning electron microscopy}

Scanning electron microscopy (SEM) of G-C scaffold was performed using a JEOL JSM-6490LV SEM.

\subsection{Raman spectroscopy}

Raman spectroscopy (JobinYvon Horiba HR800 Raman spectrometer, Japan) with $632.8 \mathrm{~nm}$ diode laser excitation on a 300 lines $\mathrm{mm}^{-1}$ grating was used to characterize the coated GO or graphene layer structure of GO-cellulose scaffold or G-C scaffold, respectively.

\subsection{X-ray photoelectron spectroscopy}

X-ray photoelectron spectroscopy (XPS) was performed with a SPECS PHOIBOS 100 Analyser (Japan) and an $\mathrm{Al} \mathrm{K}(1486.6 \mathrm{eV}) \mathrm{X}$-ray source to characterize surface states of 
synthesized G-C scaffold, GO-cellulose scaffold and uncoated cellulose scaffold. Obtained XPS data were analysed with CasaXPS2.3.16 software package.

\subsection{Electrochemical characterisation}

Cyclic voltammetry (CV) and electrochemical impedance spectroscopy (EIS) were performed using a CHI660D potentiostat. An Au electrode $(5 \mathrm{~mm} \times 20 \mathrm{~mm})$ was prepared by cutting Au-coated Mylar film with a working size of $5 \mathrm{~mm} \times 5 \mathrm{~mm}$, and a G-C scaffold electrode $(5 \mathrm{~mm} \times 20 \mathrm{~mm})$ was prepared by gluing a G-C scaffold electrode onto a polystyrene film with a working size of $5 \mathrm{~mm} \times 5 \mathrm{~mm}$. Measurements were performed using a threeelectrode setup, with the tested electrode (Au electrode or G-C scaffold electrode) as the working electrode, and a platinum $(\mathrm{Pt})$ wire and silver $(\mathrm{Ag}) /$ silver chloride $(\mathrm{AgCl})$ electrode serving as a counter electrode and reference electrode, respectively. Testing was carried out in phosphate buffered saline (PBS) solution (1x, pH 7.4). For CV, the potential of a working electrode was swept between $-1.5 \mathrm{~V}$ to $1.0 \mathrm{~V}$ with a scan rate of $0.1 \mathrm{~V} / \mathrm{s}$. For EIS, measurements were performed between $0.1 \mathrm{~Hz}$ to $100 \mathrm{kHz}$ using RMS AC signal with an amplitude of 10 $\mathrm{mV}$. Electrode stability was tested with multiple CV scanning at a scan rate of $1 \mathrm{~V} / \mathrm{s}$ between $-1.5 \mathrm{~V}$ to $1.0 \mathrm{~V}$. EIS was performed afterwards for comparative performance of electrode initial impedance.

\subsection{ADSC culture and differentiation}

ADSCs were cultured in ADSC growth medium (initial cell seeding density: $2 \times 10^{4}$ cells per $\mathrm{cm}^{2}$ for working ADSC stock culture), consisting of DMEM with $1 \%$ penicillinstreptomycin, $10 \%$ FBS, $1 \%$ NEAA, $1 \mathrm{ng} / \mathrm{ml} \mathrm{bFGF}$. Cell cultures were incubated in a humidified atmosphere at $37{ }^{\circ} \mathrm{C}$ with $5 \% \mathrm{CO}_{2}$. For ADSC differentiation, cells were maintained for a minimum of 2 weeks in growth medium supplemented with $50 \mu \mathrm{M}$ L-ascorbic acid-2phosphate, $10 \mathrm{nM}$ dexamethasone and $10 \mathrm{mM} \beta$-glycerophosphate (differentiation medium) [25]. For both ADSC culture and differentiation, media were changed every 2 days.

\subsection{Live/dead ADSC analysis}


Live ADSCs were stained using calcein AM $(5 \mu \mathrm{g} / \mathrm{ml})$ and dead cells were stained using

2 PI $(1 \mu \mathrm{g} / \mathrm{ml})$ according to the manufacturer's instructions. Scaffolds with cells were incubated with the reagents at $37{ }^{\circ} \mathrm{C}$ in a humidified atmosphere with $5 \% \mathrm{CO}_{2}$ for $30 \mathrm{~min}$. Images were obtained using an AxioImager microscope (Zeiss, Germany) following a media change.

\subsection{Optimization of applied voltage for ES}

ADSCs were cultured in the ES device with ADSC growth medium (initial cell seeding density: 4 x $10^{4}$ cells per $\mathrm{cm}^{2}$ ). An A310 Accupulser Digital Stimulator (World Precision Instruments, USA) was used to generate stimulation waveforms and A365 Stimulus Isolators (World Precision Instruments, USA) were used to transform waveforms into current output, while the system was monitored by an e-corder system (eDAQ Pty Ltd, Australia). The following day, the devices with cells were subjected to $1 \mathrm{~h}$ symmetric biphasic square pulses at $0 \mathrm{~V} / \mathrm{cm}, 1 \mathrm{~V} / \mathrm{cm}, 10 \mathrm{~V} / \mathrm{cm}$ and $20 \mathrm{~V} / \mathrm{cm}$ with phase duration of $1 \mathrm{~s}$ and interphase interval of $200 \mathrm{~ms}$, respectively. The ES settings were based on previously published research $[14,15]$, with biphasic stimulation chosen to prevent excessive charge accumulation at the electrodecell/tissue interface that could result in cell/tissue damage [26, 27]. In addition, excessive charge accumulation at the electrodes can hinder the flow of current from the stimulating electrodes [28]. Following stimulation, cells were assessed 3-4 h later by live/dead cell analysis.

\subsection{ADSC alignment analysis}

Cells were seeded onto the substrate at $2.6 \times 10^{4}$ cells per $\mathrm{cm}^{2}$ in the ES device. ES (symmetric biphasic square pulses: $1 \mathrm{~V} / \mathrm{cm}, 1 \mathrm{~Hz}, 200 \mathrm{~ms}$, $1 \mathrm{~h}$ per day) was initiated the following day, with culture medium refreshed every 2 days over the culture period. Orientation of calcein AM and PI labelled ADSCs cultured on G-C scaffolds for 28 days with or without ES was quantitatively analysed with ImageJ, whereby $0^{\circ}$ was defined as cell alignment parallel to electric current flow direction and $90^{\circ}$ defined as cell alignment perpendicular to electric current flow direction. 


\subsection{ADSC proliferation analysis}

Cells were seeded into growth medium at $2.6 \times 10^{4}$ cells per $\mathrm{cm}^{2}$ in the ES device. ES (symmetric biphasic square pulses: $1 \mathrm{~V} / \mathrm{cm}, 1 \mathrm{~Hz}, 200 \mathrm{~ms}$ ) was initiated the following day, with growth medium refreshed every 2 days over the culture period. ES was applied $1 \mathrm{~h}$ per day over 21 days and cell proliferation was determined with PrestoBlue ${ }^{\circledR}$ cell viability reagent on 1, 3, 7, 14 and 21 days in accordance with the manufacturer`s instructions. Fluorescence intensity of the samples was measured with a microplate reader (POLARstar Omega, Germany) at $544(\mathrm{ex}) / 590-10(\mathrm{em}) \mathrm{nm}$.

\subsection{Mineral deposition analysis}

ADSCs were seeded into growth medium or differentiation medium at a density of 1.5 $\mathrm{x} 10^{4}$ cells per $\mathrm{cm}^{2}$ in the ES device. Culture media were changed every 2 days. ES (symmetric biphasic square pulses: $1 \mathrm{~V} / \mathrm{cm}, 1 \mathrm{~Hz}, 200 \mathrm{~ms}$ ) was initiated the next day, with non-ES cultures concomitantly maintained. ES was applied $1 \mathrm{~h}$ per day over 3 weeks, and all study samples were subsequently fixed in $3.7 \%$ paraformaldehyde/PBS solution for $30 \mathrm{~min}$ and rinsed in Milli-Q water. Samples were then stained with Alizarin Red-S solution (0.6\%, pH 4.2) for 20 min at room temperature followed by several rinses with Milli-Q water. Stained samples were processed in $20 \%$ methanol and $10 \%$ acetic acid for 30 min, after which $200 \mu 1$ of the solution from each sample was transferred into a 96-well plate and screened for absorbance with a microplate reader (POLARstar Omega, Germany) at $450 \mathrm{~nm}$.

\subsection{Alkaline phosphatase analysis}

Cells were seeded into growth medium or differentiation medium at a cell density of $1.5 \times 10^{5}$ cells per $\mathrm{cm}^{2}$ in the ES device. ES (symmetric biphasic square pulses: $1 \mathrm{~V} / \mathrm{cm}, 1 \mathrm{~Hz}$, $200 \mathrm{~ms}, 1 \mathrm{~h}$ per day) was applied the next day after cell seeding, while control samples without ES treatment were also prepared. Culture media were changed every 2 days. Intracellular ALP activity of cells was measured by performing an ALP activity assay (BioVision, USA) on days $1,3,7$, and 14 of cell culture, according to the manufacturer's instructions. Briefly, $300 \mu 1$ Assay Buffer was added to each chamber of the device and incubated for $30 \mathrm{~min}$ at $37{ }^{\circ} \mathrm{C}$. Then, $0.5 \mathrm{mM}$ phosphatase substrate solution was mixed with the obtained ALP-containing 
1 lysis solution for a reaction time of $30 \mathrm{~min}$ at $25{ }^{\circ} \mathrm{C}$ under light-proof conditions. The resultant solution from each sample was transferred into a 96-well plate and screened for absorbance using a microplate reader (POLARstar Omega, Germany) at 360 (ex)/440 (em) nm.

\subsection{Statistical analysis}

All the experiments were performed in triplicate and data are represented as mean \pm standard deviation (SD) unless otherwise indicated. Results were analysed using two-way ANOVA with Bonferroni`s post hoc test (OriginPro 2015). Homogeneity of variance tests (Levene`s Test) were performed to confirm statistical assumptions for two-way ANOVA were satisfied. If homogeneity of variance was satisfied $(\mathrm{P}>0.05)$, statistical significance of twoway ANOVA was set at $\mathrm{P}<0.05$. If homogeneity of variance was not satisfied $(\mathrm{P}<0.05)$, statistical significance of two-way ANOVA was set at $\mathrm{P}<0.01$.

\section{Results and discussion}

\subsection{Material characterisation}

Morphology and microstructure of the G-C scaffold were assessed by SEM (Fig. 2AC). Graphene was uniformly deposited onto the cellulose substrate and showed porous features decorated through the structure (Fig. 2A). Cellulose fibres were entirely coated with graphene and graphene layers bridged between fibres (Fig. 2B-C). Raman spectrum shows two characteristic features of graphitic material structures, i.e. D band $\left(\sim 1330 \mathrm{~cm}^{-1}\right)$ and $\mathrm{G}$ band $\left(\sim 1580 \mathrm{~cm}^{-1}\right)$ (Fig. 2D and S1A). The bands reflect graphene structure disorders and degree of graphitization, respectively [29]. $\mathrm{I}_{\mathrm{D}} / \mathrm{I}_{\mathrm{G}}$ (Ratio of $\mathrm{D}$ band and $\mathrm{G}$ band intensities) were $\sim 1.10$ (GO-cellulose scaffold) and $\sim 1.56$ (G-C scaffold), which demonstrates restoration of $\mathrm{sp}^{2}$ carbon during reduction and defects acquired in the oxidation/reduction process [30]. Moreover, the 2D band ( 2630) and S3 band ( 2880) of G-C scaffold increased compared with GOcellulose scaffold after chemical reduction, indicative of improved graphitization of G-C scaffold $[31,32]$. XPS verified differences between oxidized carbon functional groups of G-C scaffold, GO-cellulose scaffold, and uncoated cellulose scaffold (Fig. 2E and S1B-C). The C 1s spectra were deconvoluted into five carbon related functional groups, which mainly consist of $\mathrm{C}=\mathrm{C}, \mathrm{C}-\mathrm{C}, \mathrm{C}-\mathrm{O}, \mathrm{C}=\mathrm{O}$ and $\mathrm{O}-\mathrm{C}=\mathrm{O}$ at 284.8, 285.6, 286.8, 287.8 and 289.1, respectively [33]. 
1 Referring to Fig. S1B-C, C=C, C=O and O-C=O groups appeared following GO coating of cellulose scaffold, affirming coating procedure. The oxidized carbon ratio decreased from 53.9\% (GO-cellulose scaffold) to $39.2 \%$ (G-C scaffold), indicating efficient de-oxygenation processed through chemical reduction of GO.

\subsection{Electrode characterisation}

Electrochemical performance of G-C scaffold electrode was investigated and compared with Au electrode. CV was used to determine the charge storage capacity (Fig. 3A). Due to the enhanced water window of carbon material compared with metal material [34], charge storage capacity of G-C electrode $\left(0.966 \mathrm{mC} / \mathrm{cm}^{2}\right)$ was 1.09 fold higher than that of Au electrode $(0.462$ $\mathrm{mC} / \mathrm{cm}^{2}$ ). Increased charge storage capacity supports the use of G-C scaffold electrode for ES application due to its capacity for transferring charge. As shown in Fig. 3B, G-C scaffold electrode showed lower impedance compared with Au electrode at low frequencies (0.1-150 $\mathrm{Hz}$ ), indicating its energy efficiency with higher charge injection capability [35]. Reduced electrode impedance can also influence the noise of electronics and electrical interference of the electrode itself, further supporting its potential for additional scaling down [36]. Furthermore, EIS and surface morphology of G-C scaffold electrode remained stable after 1000 treated cycles during CV (Fig. S2A-B), indicative of stable performance over long-term ES.

\subsection{Characterisation of assembled ES device}

The G-C scaffold-based ES device comprised ES chambers for culturing and treating cells in vitro (Fig. 4A-B). The fabrication strategy is flexible for scale-up both in terms of number of chambers included and working area for cell culture and ES. For ES, symmetric biphasic square pulses with a calculated electrical field generation ranging from 0 to $20 \mathrm{~V} / \mathrm{cm}$ at a frequency of $1 \mathrm{~Hz}$ and pulse of $200 \mathrm{~ms}$ were applied (Fig. 4C).

\subsection{Evaluation of ES on ADSC viability under different applied voltages}

Since the magnitude of the biphasic square pulses has an effect on cell viability, a series of electrical fields with different strengths were applied to determine optimal ES. As shown in 
1 Fig. 5A-D, higher electrical fields (10 and $20 \mathrm{~V} / \mathrm{cm})$ were associated with markedly higher levels of dead cells, while a lower electrical field $(1 \mathrm{~V} / \mathrm{cm})$ had no adverse effect on cell viability. Therefore, $1 \mathrm{~V} / \mathrm{cm}$ with a current density of approximately $300 \mu \mathrm{A} / \mathrm{cm}^{2}$ was applied for subsequent ES experiments.

\subsection{Evaluation of long-term ES on ADSC viability and orientation}

Applied electric current can direct the orientation of cells, with cells on supporting GC scaffold observed to have alignment perpendicular to the electric current direction following 5 days culture and ES (Fig. 6 A-B), which is consistent with previous reports [37, 38]. This phenomenon may be relevant to ADSC differentiation based on published evidence for stem cell alignment affecting cell fate [39]. Also notable, high cell viability with no visible signs of scaffold degradation were apparent after 28 days culture with ES, supporting the use of the platform for longer-term cell support, including differentiation for tissue formation, evaluation and, therefore, modelling (Fig. S3A). The probability density of cell orientation has a narrow peak near $90^{\circ}$ for ADSCs cultured with ES (Fig. S3A-B), while ADSCs cultured without ES showed random orientation (Fig. S3C-D). Importantly, the supporting G-C scaffolds remained intact and conductive after 28 days ES, further validating their stability and application as longterm electrical conductors.

\subsection{Effect of ES on proliferation and osteogenic differentiation of ADSCs}

Exogenous ES can alter cell transmembrane potential, which may have a positive effect on cell proliferation [12]. As shown in Fig. 7, ES for 21 days resulted in a continuing increase in ADSC proliferation for the duration of study, while proliferation of cells without ES increased up to Day 14. The number of cells in samples with ES on Day 21 was 1.6 fold higher than the peak value for samples without ES on Day 14. Statistical analysis revealed that ES (F $(1,50)=306.32, P<0.0001)$ and day $(\mathrm{F}(4,50)=519.36, P<0.0001)$ significantly affected cell proliferation, as well as the interaction between ES and day (Overall two-way ANOVA, F $(4,50)=23.81, P<0.0001)$. More specifically, Bonferroni-post hoc analysis indicated that ADSC proliferation with or without ES treatment was significantly different $(P<0.01)$, except for day 14 and day 21 . These data corroborate our previous report of the cytocompatibility of 
1 G-C scaffold [20], and substantiate the ES device for augmenting cell growth over extended culture and stimulation.

Mineral deposition is a key indicator of ADSC osteogenic differentiation [40]. After being stained with Alizarin Red S, more extracellular mineral deposition of ADSCs could be observed on G-C scaffold electrodes in osteogenic differentiation medium, being further enhanced by ES treatment (Fig. 8A-D). Quantifying by colorimetric detection demonstrated higher mineral deposition of samples cultured in differentiation medium compared to normal growth medium, with the effect of differentiation medium significantly bolstered by ES (Fig. 8E). Statistical analysis revealed that ES $(\mathrm{F}(1,20)=122.94, P<0.0001)$ and medium $(\mathrm{F}(1$, $20)=193.60, P<0.0001)$ significantly affected ADSC mineral deposition, as well as the interaction between ES and medium (Overall two-way ANOVA, F $(1,20)=82.38, P<0.0001$ ). Specifically, Bonferroni-post hoc analysis indicated that mineral deposition of ADSCs was significantly different with or without ES treatment $(P<0.01)$, and with different culture medium $(P<0.01)$. Overall, ES can accelerate the osteogenic differentiation of ADSC, which is consistent with previous reports [8].

As an early osteogenesis marker [41], ALP expression in ADSCs was quantitatively analysed, indicating that ALP expression within ADSCs cultured in differentiation medium with ES treatment (ADSCs+DIF+ES) was significantly higher than ADSCs cultured in growth medium with ES (ADSCs+GRO+ES) and ADSCs in osteogenic differentiation medium without ES (ADSCs+DIF) (Fig. 9). This phenomenon may be due to the synergistic effect of ES and osteogenic induction factors in differentiation medium. Expression of ALP peaked at Day 7 for ADSCs+GRO+ES and ADSCs+DIF, but continued to increase for ADSCs+DIF +ES. ALP activity for ADSCs+DIF+ES at Day 14 was 3.6 fold and 2.7 fold higher than the peak value of ADSCs+GRO+ES and ADSCs+DIF, respectively. Not surprisingly, ALP expression for ADSCs+GRO+ES was similar to that for ADSCs+DIF, indicating an inductive effect of ES and graphene on osteogenic differentiation, independent of other inducers, which is consistent with previous reports $[7,15]$. Statistical analysis revealed that both ES $(\mathrm{F}(2,60)$ $=75.08, P<0.0001)$ and day $(\mathrm{F}(3,60)=43.13, P<0.0001)$ significantly affected ALP activity within ADSCs, as well as the interaction between ES and day (Overall two-way ANOVA, F $(6,60)=24.12, P<0.0001)$. Specifically, Bonferroni-post hoc analysis indicated that ALP activity within ADSCs was significantly different with or without ES $(P<0.01)$, and with 
different culture medium $(P<0.01)$. These results further demonstrate augmentation of ES on osteogenic differentiation of ADSCs [42].

\section{Conclusion}

We present here the fabrication and utility of a miniaturized, multi-chamber ES device that incorporates our previously described cell supporting G-C scaffold. The as-developed ES device can be employed for in vitro ADSC proliferation and osteogenic differentiation without compromising the integrity and electrical performance of the G-C scaffold for at least 21 days. The device can be easily assembled with our previously developed conductive G-C scaffold and commercially available cell culture chamber(s), with further development of more complicated and customized ES devices being feasible. ADSCs stimulated by biphasic square pulses via the ES device showed increased proliferation, mineral deposition and ALP expression compared to control samples without ES treatment. Altogether, studies of our platform demonstrate efficacy for stable cell support and enhanced differentiation over extended culture with ES, consistent with previous reports of external stimulation effects on cells [13-15]. The device may be useful in research for tissue engineering and modelling, as well as prospective therapeutics, including preclinical assays for drug screening and tissue development for regenerative medicine. The latter is supported by evidence for graphene based materials being able to promote in vivo bone repair and reconstruction [43, 44], in vivo biocompatibility of cellulose [45], and the recognised benefits of ES for bone healing.

\section{Acknowledgements}

JL, XL, GGW and JMC conceived the study. JL executed the experiments. JL and JMC wrote the paper and all authors commented on the paper. JMC and GGW are co-senior corresponding authors. The authors wish to acknowledge funding from the Australian Research Council (ARC) Centre of Excellence Scheme (CE140100012), equipment support by the Australian National Fabrication Facility (ANFF)-Materials Node, and the use of facilities at the University of Wollongong Electron Microscopy Centre (EMC). GGW acknowledges the support of the ARC through an ARC Laureate Fellowship (FL110100196). GGW and XL acknowledge the support of the ARC Industrial Transformation Training Centre in Additive 
1 Biomanufacturing (IC160100026). JL would like to thank AINSE Ltd for providing financial assistance. The authors would also like to thank Assoc. Prof. Chee O. Too for his valuable comments on the manuscript, Dr Kerry Gilmore for technical support in cell related experiments, Dr Patricia Hayes for Raman measurements and Dr Dongqi Shi for support with XPS measurements.

\section{References}

[1] A. Leventhal, G. Chen, A. Negro, M. Boehm, The benefits and risks of stem cell technology, Oral Dis 18(3) (2012) 217-222.

[2] M.S. Carvalho, J.C. Silva, R.N. Udangawa, J.M.S. Cabral, F.C. Ferreira, C.L. da Silva, R.J. Linhardt, D. Vashishth, Co-culture cell-derived extracellular matrix loaded electrospun microfibrous scaffolds for bone tissue engineering, Materials Science and Engineering: C 99 (2019) 479-490.

[3] Kenry, W.C. Lee, K.P. Loh, C.T. Lim, When stem cells meet graphene: Opportunities and challenges in regenerative medicine, Biomaterials 155 (2018) 236-250.

[4] R. Augustine, P. Prasad, I.M.N. Khalaf, Therapeutic angiogenesis: From conventional approaches to recent nanotechnology-based interventions, Materials Science and Engineering: C 97 (2019) 994-1008.

[5] H. Xie, T. Cao, J.V. Gomes, A.H. Castro Neto, V. Rosa, Two and three-dimensional graphene substrates to magnify osteogenic differentiation of periodontal ligament stem cells, Carbon 93 (2015) 266-275.

[6] H. Xie, M. Chua, I. Islam, R. Bentini, T. Cao, J.C. Viana-Gomes, A.H. Castro Neto, V. Rosa, CVD-grown monolayer graphene induces osteogenic but not odontoblastic differentiation of dental pulp stem cells, Dental Materials 33(1) (2017) e13-e21. 
1 [7] W.-W. Hu, Y.-T. Hsu, Y.-C. Cheng, C. Li, R.-C. Ruaan, C.-C. Chien, C.-A. Chung, C.-W.

2 Tsao, Electrical stimulation to promote osteogenesis using conductive polypyrrole films,

3 Materials Science and Engineering: C 37(Supplement C) (2014) 28-36.

4 [8] J. Zhang, M. Li, E.T. Kang, K.G. Neoh, Electrical stimulation of adipose-derived 5 mesenchymal stem cells in conductive scaffolds and the roles of voltage-gated ion channels, $6 \quad$ Acta biomaterialia 32 (2016) 46-56.

7 [9] J. Wang, L. Tian, N. Chen, S. Ramakrishna, X. Mo, The cellular response of nerve cells on 8 poly-l-lysine coated PLGA-MWCNTs aligned nanofibers under electrical stimulation, $9 \quad$ Materials Science and Engineering: C 91 (2018) 715-726.

10 [10] Z.-Q. Feng, K. Yan, C. Shi, X. Xu, T. Wang, R. Li, W. Dong, J. Zheng, Neurogenic 11 differentiation of adipose derived stem cells on graphene-based mat, Materials Science and Engineering: C 90 (2018) 685-692.

[11] Y.-J. Chang, C.-M. Hsu, C.-H. Lin, M.S.-C. Lu, L. Chen, Electrical stimulation promotes nerve growth factor-induced neurite outgrowth and signaling, Biochimica et Biophysica Acta (BBA) - General Subjects 1830(8) (2013) 4130-4136.

[12] M.R. Love, S. Palee, S.C. Chattipakorn, N. Chattipakorn, Effects of electrical stimulation on cell proliferation and apoptosis, Journal of Cellular Physiology 233(3) (2018) 1860-1876.

[13] M. Eischen-Loges, K.M. Oliveira, M.B. Bhavsar, J.H. Barker, L. Leppik, Pretreating mesenchymal stem cells with electrical stimulation causes sustained long-lasting proosteogenic effects, PeerJ 6 (2018) e4959.

[14] S. Mobini, L. Leppik, V. Thottakkattumana Parameswaran, J.H. Barker, In vitro effect of direct current electrical stimulation on rat mesenchymal stem cells, PeerJ 5 (2017) e2821e2821. 
1 [15] Z. Liu, L. Dong, L. Wang, X. Wang, K. Cheng, Z. Luo, W. Weng, Mediation of cellular

2 osteogenic differentiation through daily stimulation time based on polypyrrole planar

3 electrodes, Scientific Reports 7(1) (2017) 17926.

4 [16] L.M. Cross, A. Thakur, N.A. Jalili, M. Detamore, A.K. Gaharwar, Nanoengineered

5 biomaterials for repair and regeneration of orthopedic tissue interfaces, Acta biomaterialia 42

6 (2016) 2-17.

7 [17] J. Li, X. Liu, J.M. Crook, G.G. Wallace, Development of a porous 3D graphene-PDMS

8 scaffold for improved osseointegration, Colloids and Surfaces B: Biointerfaces 159 (2017)

$9 \quad 386-393$.

10 [18] R. Geetha Bai, N. Ninan, K. Muthoosamy, S. Manickam, Graphene: A versatile platform

11 for nanotheranostics and tissue engineering, Progress in Materials Science 91(Supplement C) 12 (2018) 24-69.

[19] A. Marrella, G. Tedeschi, P. Giannoni, A. Lagazzo, F. Sbrana, F. Barberis, R. Quarto, F.

Puglisi, S. Scaglione, "Green-reduced" graphene oxide induces in vitro an enhanced biomimetic mineralization of polycaprolactone electrospun meshes, Materials Science and Engineering: C 93 (2018) 1044-1053.

[20] J. Li, X. Liu, E. Tomaskovic-Crook, J.M. Crook, G.G. Wallace, Smart graphene-cellulose paper for $2 \mathrm{D}$ or $3 \mathrm{D}$ "origami-inspired" human stem cell support and differentiation, Colloids and Surfaces B: Biointerfaces 176 (2019) 87-95.

[21] H. Chen, M.B. Müller, K.J. Gilmore, G.G. Wallace, D. Li, Mechanically Strong, Electrically Conductive, and Biocompatible Graphene Paper, Advanced materials 20(18) (2008) 3557-3561.

[22] P. Gupta, A. Agrawal, K. Murali, R. Varshney, S. Beniwal, S. Manhas, P. Roy, D. Lahiri,

Differential neural cell adhesion and neurite outgrowth on carbon nanotube and graphene reinforced polymeric scaffolds, Materials Science and Engineering: C 97 (2019) 539-551. 
1 [23] W.S. Hummers, R.E. Offeman, Preparation of Graphitic Oxide, Journal of the American

2 Chemical Society 80(6) (1958) 1339-1339.

3

4

5

6

[24] J. Zhang, H. Yang, G. Shen, P. Cheng, J. Zhang, S. Guo, Reduction of graphene oxide vial-ascorbic acid, Chemical communications 46(7) (2010) 1112-1114.

[25] L. Kyllönen, S. Haimi, B. Mannerström, H. Huhtala, K.M. Rajala, H. Skottman, G.K. Sándor, S. Miettinen, Effects of different serum conditions on osteogenic differentiation of human adipose stem cells in vitro, Stem Cell Research \& Therapy 4(1) (2013) 1-15.

[26] J.A. Spadaro, R.O. Becker, Function of implanted cathodes in electrode-induced bone growth, Medical and Biological Engineering and Computing 17(6) (1979) 769-775.

[27] D.R. Merrill, M. Bikson, J.G.R. Jefferys, Electrical stimulation of excitable tissue: design of efficacious and safe protocols, Journal of Neuroscience Methods 141(2) (2005) 171-198. [28] I.S. Kim, J.K. Song, Y.L. Zhang, T.H. Lee, T.H. Cho, Y.M. Song, D.K. Kim, S.J. Kim, S.J. Hwang, Biphasic electric current stimulates proliferation and induces VEGF production in osteoblasts, Biochimica et Biophysica Acta (BBA) - Molecular Cell Research 1763(9) (2006) 907-916.

[29] D. Graf, F. Molitor, K. Ensslin, C. Stampfer, A. Jungen, C. Hierold, L. Wirtz, Spatially Resolved Raman Spectroscopy of Single- and Few-Layer Graphene, Nano Letters 7(2) (2007) 238-242.

[30] M.E. Uddin, R.K. Layek, N.H. Kim, D. Hui, J.H. Lee, Preparation and properties of reduced graphene oxide/polyacrylonitrile nanocomposites using polyvinyl phenol, Composites Part B: Engineering 80 (2015) 238-245.

[31] P. Cui, J. Lee, E. Hwang, H. Lee, One-pot reduction of graphene oxide at subzero temperatures, Chemical communications 47(45) (2011) 12370-12372. 
1 [32] X. Chen, X. Deng, N.Y. Kim, Y. Wang, Y. Huang, L. Peng, M. Huang, X. Zhang, X.

2 Chen, D. Luo, Graphitization of graphene oxide films under pressure, Carbon 132 (2018) 294-

3

4

5

6

7

8

9

10 303.

[33] P. Wang, Z.-G. Liu, X. Chen, F.-L. Meng, J.-H. Liu, X.-J. Huang, UV irradiation synthesis of an Au-graphene nanocomposite with enhanced electrochemical sensing properties, Journal of Materials Chemistry A 1(32) (2013) 9189-9195.

[34] Y. Lu, H. Lyu, A.G. Richardson, T.H. Lucas, D. Kuzum, Flexible Neural Electrode Array Based-on Porous Graphene for Cortical Microstimulation and Sensing, Scientific Reports 6 (2016) 33526.

[35] S. Arcot Desai, J. Rolston, L. Guo, S. Potter, Improving impedance of implantable microwire multi-electrode arrays by ultrasonic electroplating of durable platinum black, Frontiers in Neuroengineering 3(5) (2010).

[36] D. Kuzum, H. Takano, E. Shim, J.C. Reed, H. Juul, A.G. Richardson, J. de Vries, H. Bink, M.A. Dichter, T.H. Lucas, D.A. Coulter, E. Cubukcu, B. Litt, Transparent and flexible low noise graphene electrodes for simultaneous electrophysiology and neuroimaging, Nature Communications 5 (2014) 5259.

[37] Y. Li, G. Huang, X. Zhang, L. Wang, Y. Du, T.J. Lu, F. Xu, Engineering cell alignment in vitro, Biotechnology Advances 32(2) (2014) 347-365.

[38] N. Tandon, B. Goh, A. Marsano, P.-H.G. Chao, C. Montouri-Sorrentino, J. Gimble, G. Vunjak-Novakovic, Alignment and elongation of human adipose-derived stem cells in response to direct-current electrical stimulation, Conference proceedings : ... Annual International Conference of the IEEE Engineering in Medicine and Biology Society. IEEE Engineering in Medicine and Biology Society. Annual Conference 2009 (2009) 6517-6521. 
1 [39] Z. Yin, X. Chen, J.L. Chen, W.L. Shen, T.M. Hieu Nguyen, L. Gao, H.W. Ouyang, The

2 regulation of tendon stem cell differentiation by the alignment of nanofibers, Biomaterials

3

4

5

6

7 31(8) (2010) 2163-2175.

[40] W. Liu, J. Lipner, J. Xie, C.N. Manning, S. Thomopoulos, Y. Xia, Nanofiber Scaffolds with Gradients in Mineral Content for Spatial Control of Osteogenesis, ACS Applied Materials \& Interfaces 6(4) (2014) 2842-2849.

[41] L. de Girolamo, M.F. Sartori, W. Albisetti, A.T. Brini, Osteogenic differentiation of human adipose-derived stem cells: comparison of two different inductive media, Journal of Tissue Engineering and Regenerative Medicine 1(2) (2007) 154-157.

[42] J.G. Hardy, M.K. Villancio-Wolter, R.C. Sukhavasi, D.J. Mouser, D. Aguilar, S.A. Geissler, D.L. Kaplan, C.E. Schmidt, Electrical Stimulation of Human Mesenchymal Stem Cells on Conductive Nanofibers Enhances their Differentiation toward Osteogenic Outcomes, Macromolecular Rapid Communications 36(21) (2015) 1884-1890.

[43] A. Hermenean, A. Codreanu, H. Herman, C. Balta, M. Rosu, C.V. Mihali, A. Ivan, S. Dinescu, M. Ionita, M. Costache, Chitosan-Graphene Oxide 3D scaffolds as Promising Tools for Bone Regeneration in Critical-Size Mouse Calvarial Defects, Scientific Reports 7(1) (2017) 16641.

[44] T. Zhou, G. Li, S. Lin, T. Tian, Q. Ma, Q. Zhang, S. Shi, C. Xue, W. Ma, X. Cai, Y. Lin, Electrospun Poly(3-hydroxybutyrate-co-4-hydroxybutyrate)/Graphene Oxide Scaffold: Enhanced Properties and Promoted in Vivo Bone Repair in Rats, ACS Applied Materials \& Interfaces 9(49) (2017) 42589-42600.

[45] P. Daugela, M. Pranskunas, G. Juodzbalys, J. Liesiene, O. Baniukaitiene, A. Afonso, P. Sousa Gomes, Novel cellulose/hydroxyapatite scaffolds for bone tissue regeneration: In vitro and in vivo study, Journal of Tissue Engineering and Regenerative Medicine 12(5) (2018) $1195-1208$. 


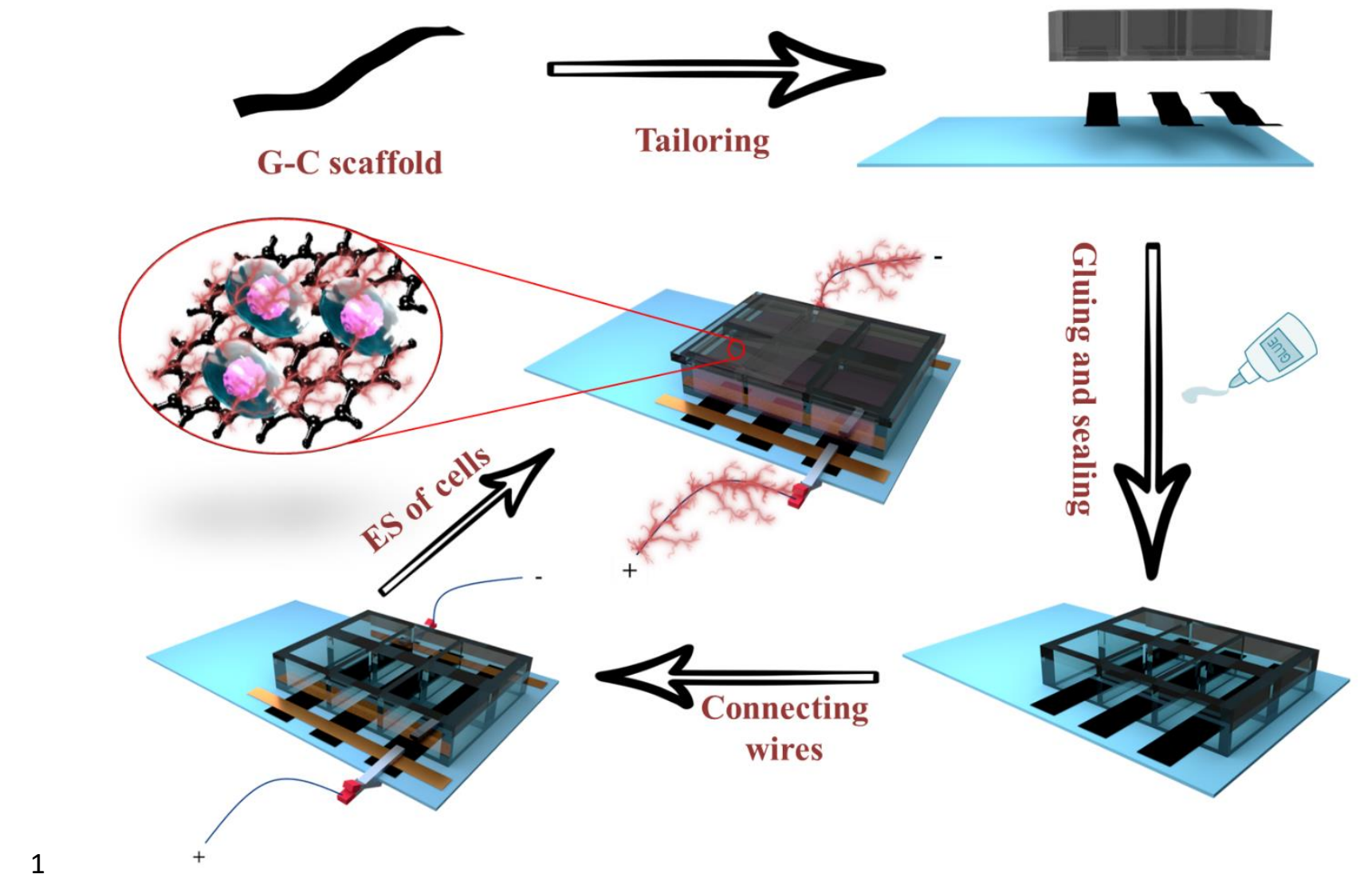

2 Fig. 1. Assembly of a G-C scaffold-based ES device. 

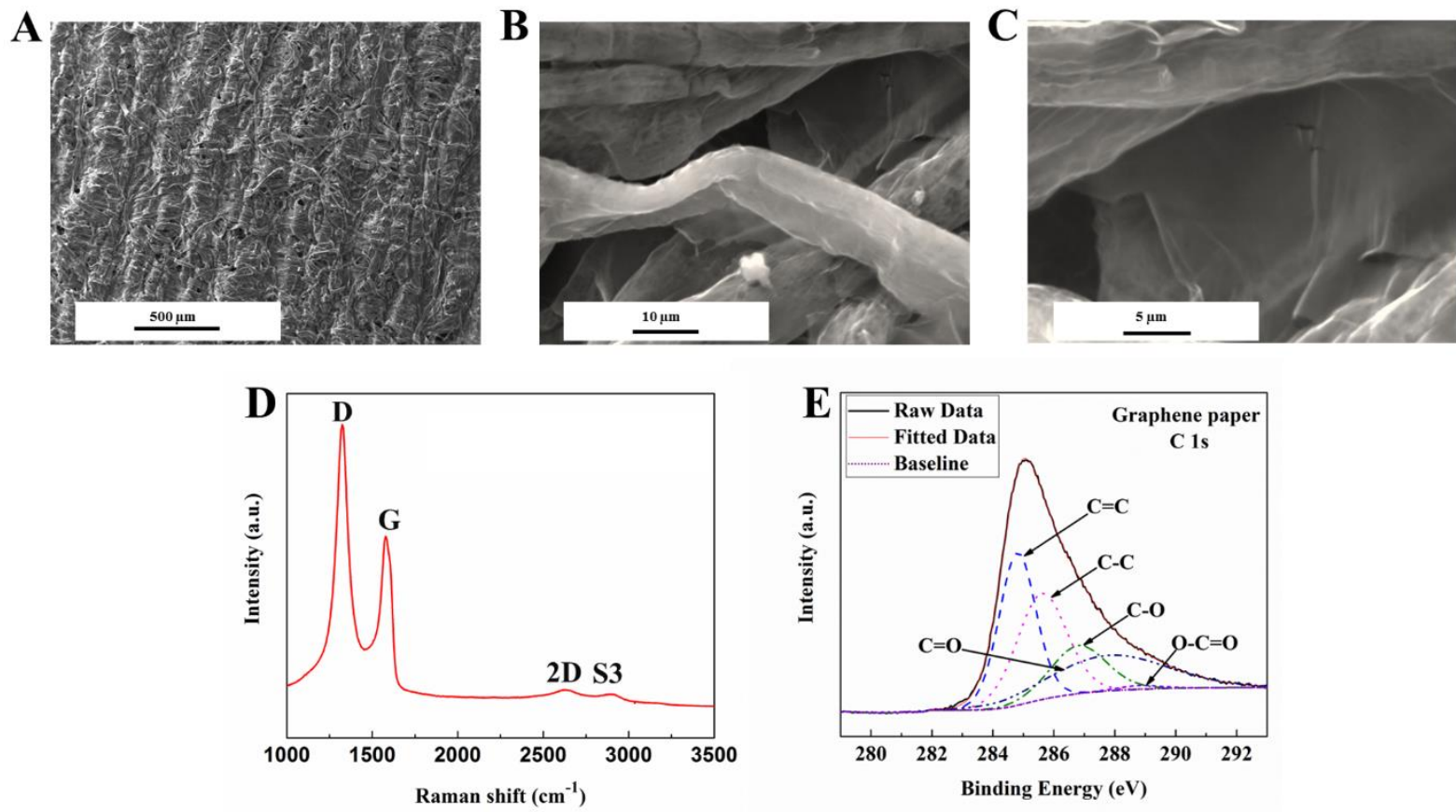

1

2 Fig. 2. Characterization of G-C scaffold. (A-C) SEM images of G-C scaffold at different 3 magnifications (X50, X2000, and X4000). (D) Raman spectrum of G-C scaffold. (E) XPS spectrum of C 1s of G-C scaffold.
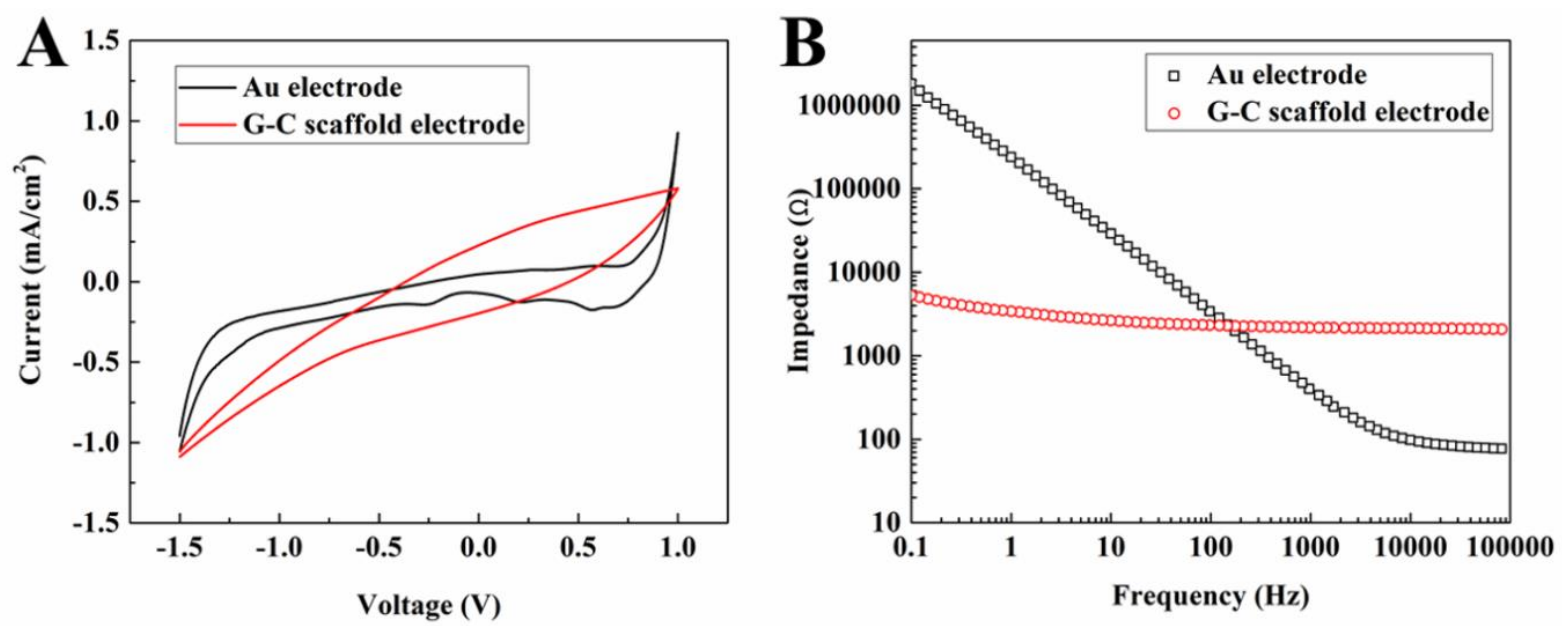

6

7 Fig. 3. Electrochemical characterisation of $\mathrm{Au}$ and G-C scaffold electrodes. (A) Cyclic 8 voltammogram and (B) EIS of Au electrode and G-C scaffold electrode. 

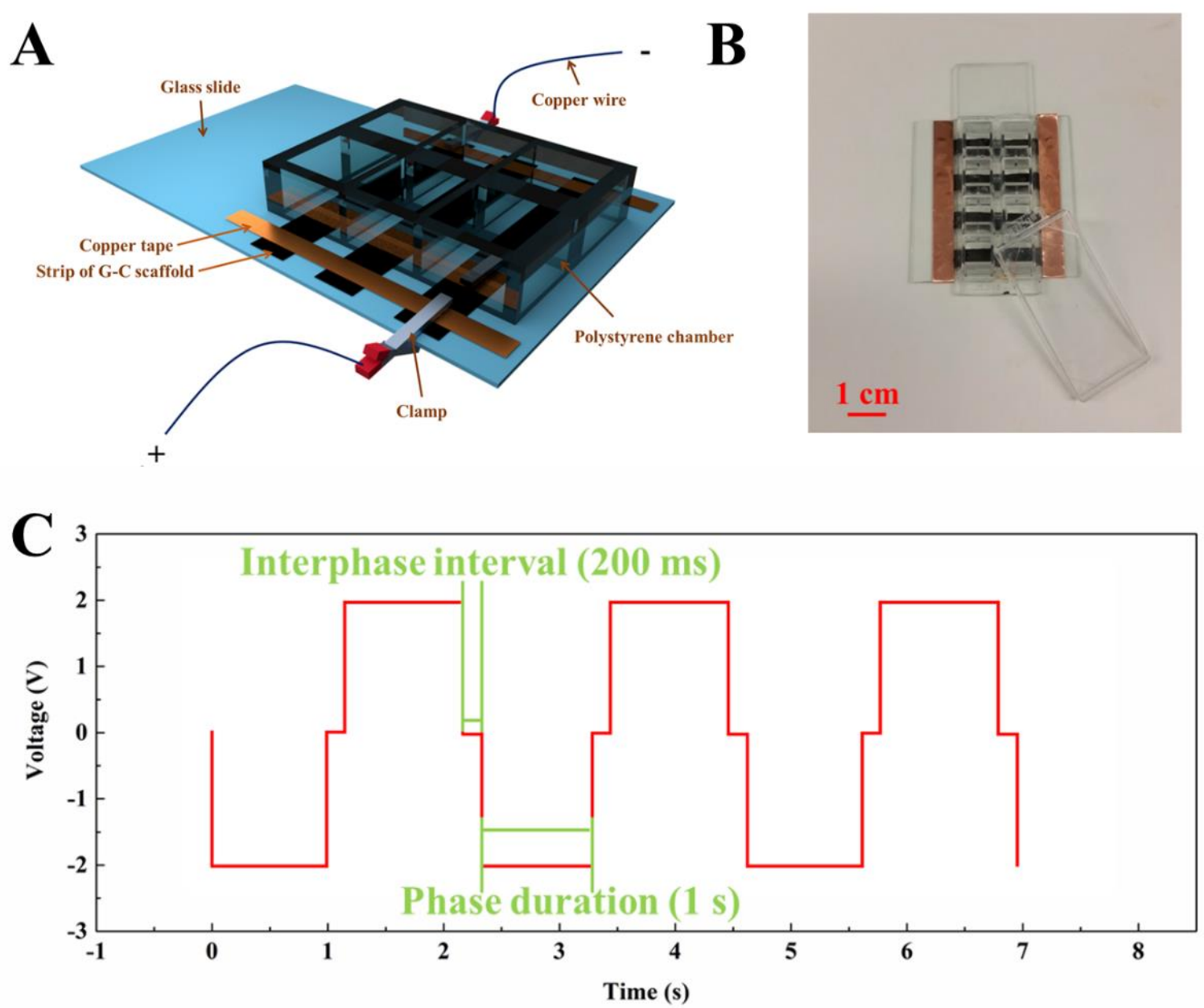

2

3 Fig. 4. Characterisation of ES device and applied ES. (A, B) Schematic and photograph of G4 C scaffold-based ES device, respectively. (C) Waveform of applied symmetric biphasic square 5 pulses via $\mathrm{G}-\mathrm{C}$ scaffold.

6 

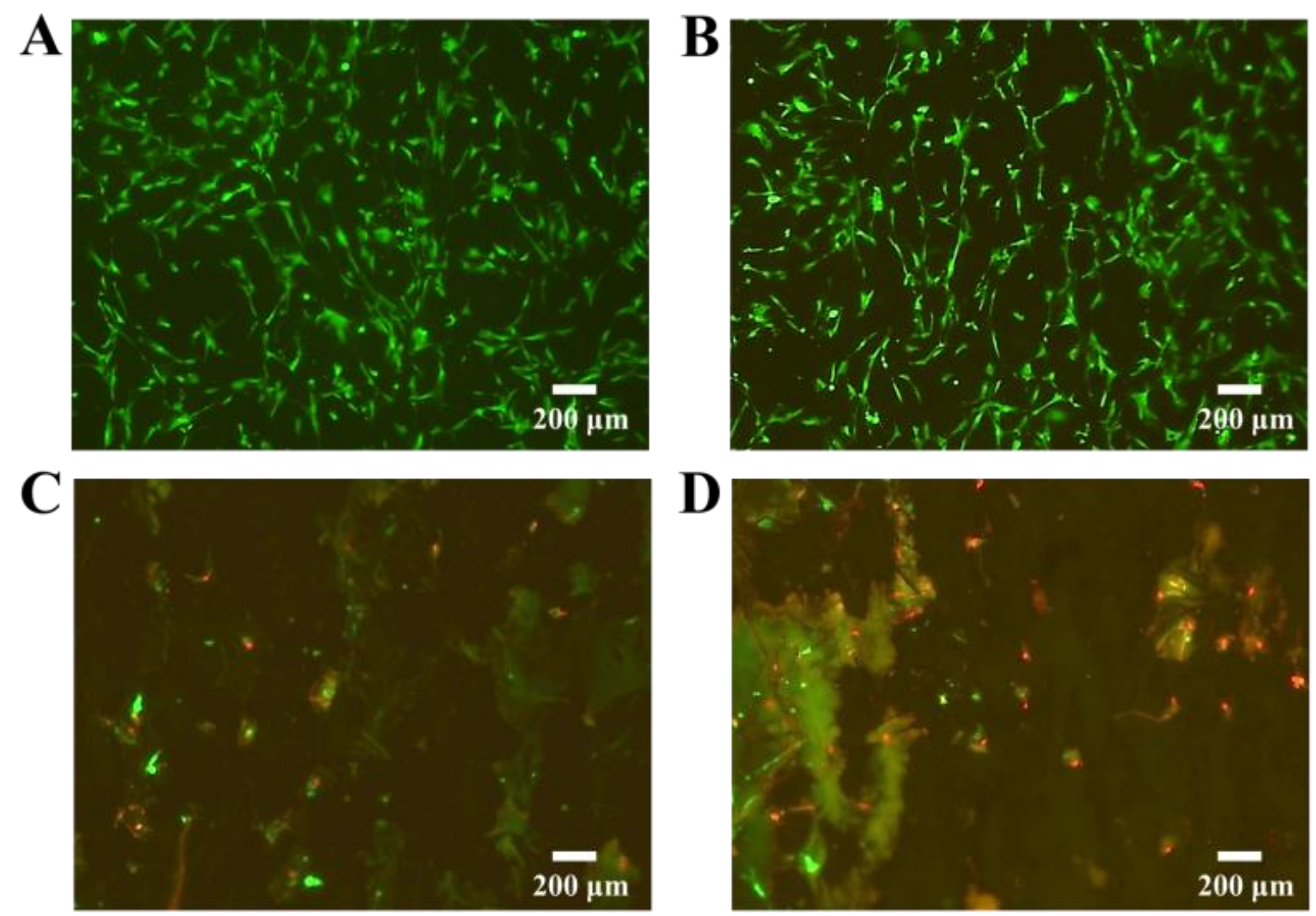

2 Fig. 5. Viability of ADSCs under different applied voltage in ES. Live (Calcein AM; green) 3 and dead (PI; red) ADSC staining following exposure for $1 \mathrm{~h}$ to electrical field (A) 0, (B) 1 , 4 (C) 10 and (D) $20 \mathrm{~V} / \mathrm{cm}$ with phase duration of $1 \mathrm{~s}$ and interphase interval of $200 \mathrm{~ms}$. 

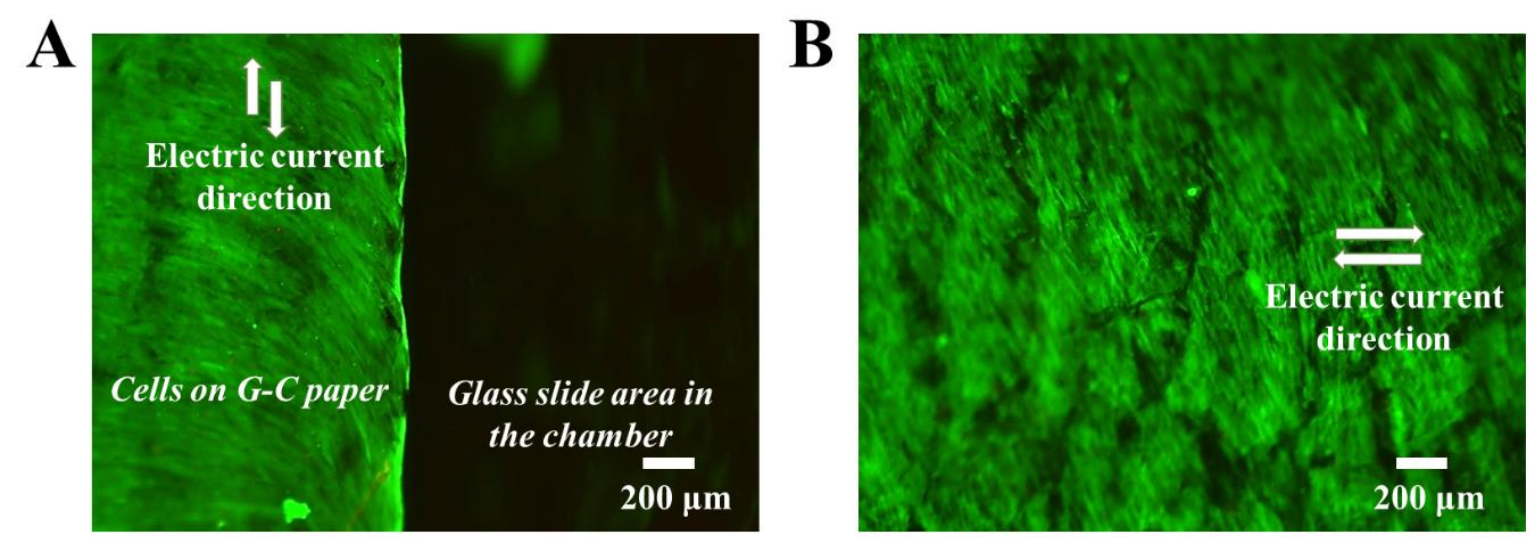

1 Fig. 6. (A, B) ADSC viability and alignment under 5 days ES. Live (Calcein AM; green) and 2 dead (PI; red) ADSC staining following 5 days culture and ES at $1 \mathrm{~V} / \mathrm{cm}$ with phase duration 3 of $1 \mathrm{~s}$ and interphase interval of $200 \mathrm{~ms}$.

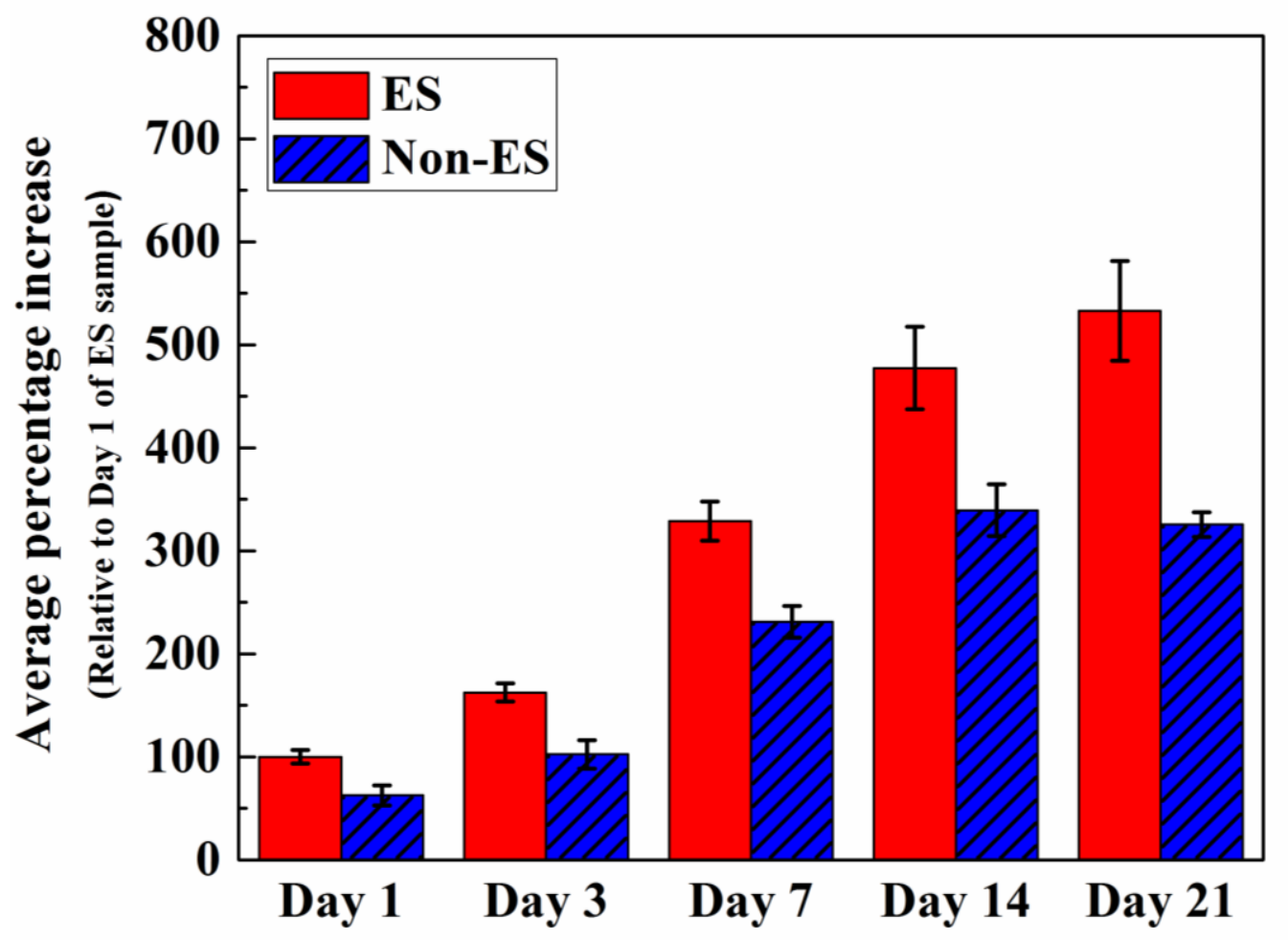

12 Fig. 7. Time course of ADSC proliferation (quantified by PrestoBlue ${ }^{\circledR}$ assay) up to day 21 of 13 cell culture in the G-C scaffold-based ES device. Mean \pm standard deviation, $\mathrm{n}=3, P<0.01$ 14 (ES Day $21 v s$ all the comparisons; ES vs Non ES on Day 3, 7 and 14; ES Day 1 vs ES Day 3, 157 and 14; ES Day 3 vs ES Day 7 and 14; ES Day 7 vs ES Day 14; Non ES Day 1 vs Non ES 16 Day7, 14 and 21; Non ES Day 3 vs Non ES Day7, 14 and 21; Non ES Day 7 vs Non ES Day 1714 and 21). 

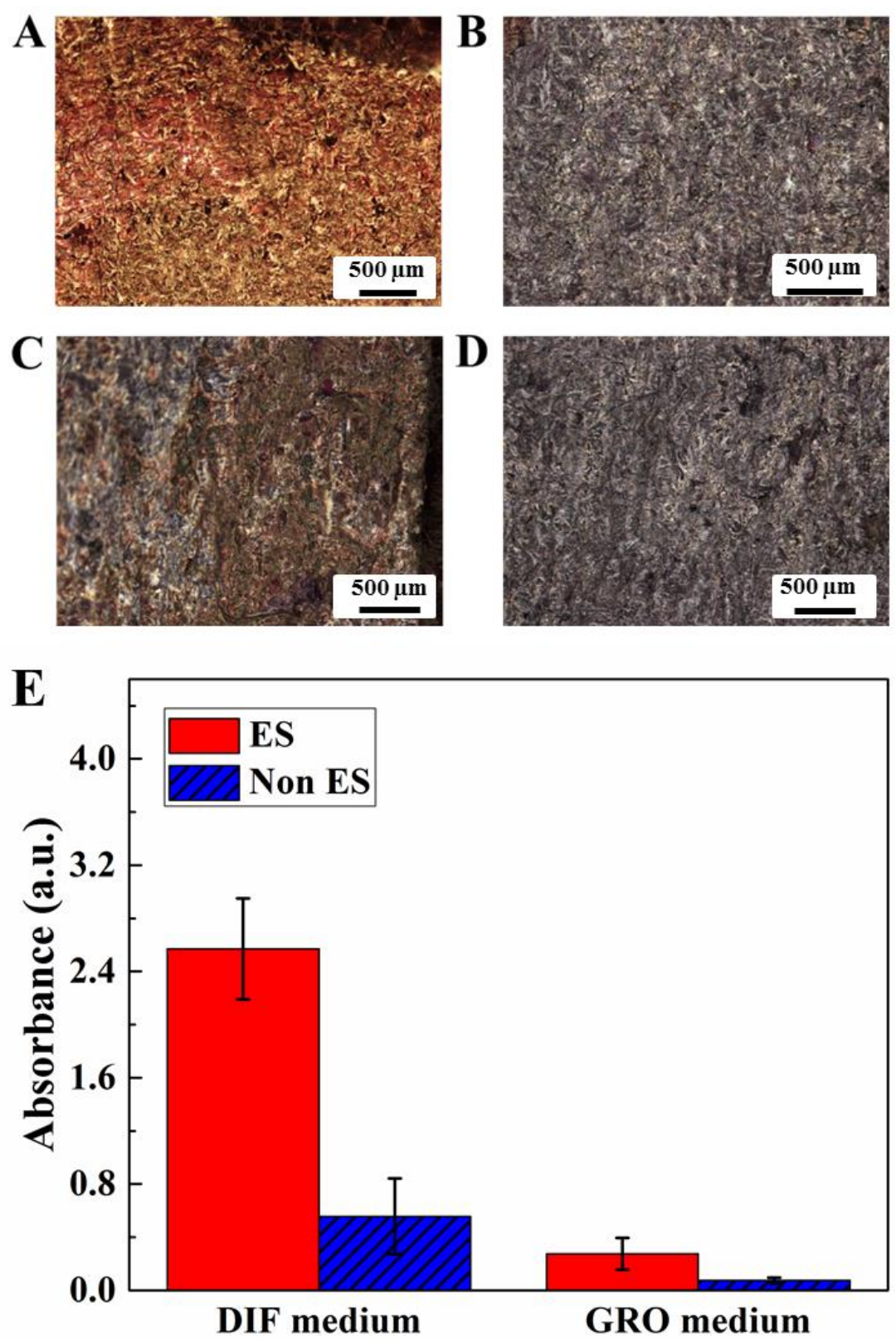

2 Fig. 8. Extracellular mineral deposition of ADSCs assessed by Alizarin Red S staining after 3 culture for 3 weeks (A) with or (C) without ES in differentiation (DIF) medium, and (B) with 4 or (D) without ES in ADSC growth (GRO) medium. (E) Mineral deposition was quantified by 5 using Alizarin Red S staining with colorimetric detection at $450 \mathrm{~nm}$. Mean \pm standard 6 deviation, $\mathrm{n}=3, P<0.01$ (DIF medium $v s$ GRO medium with both ES and Non ES; ES DIF 7 medium $v s$ Non ES DIF medium). 


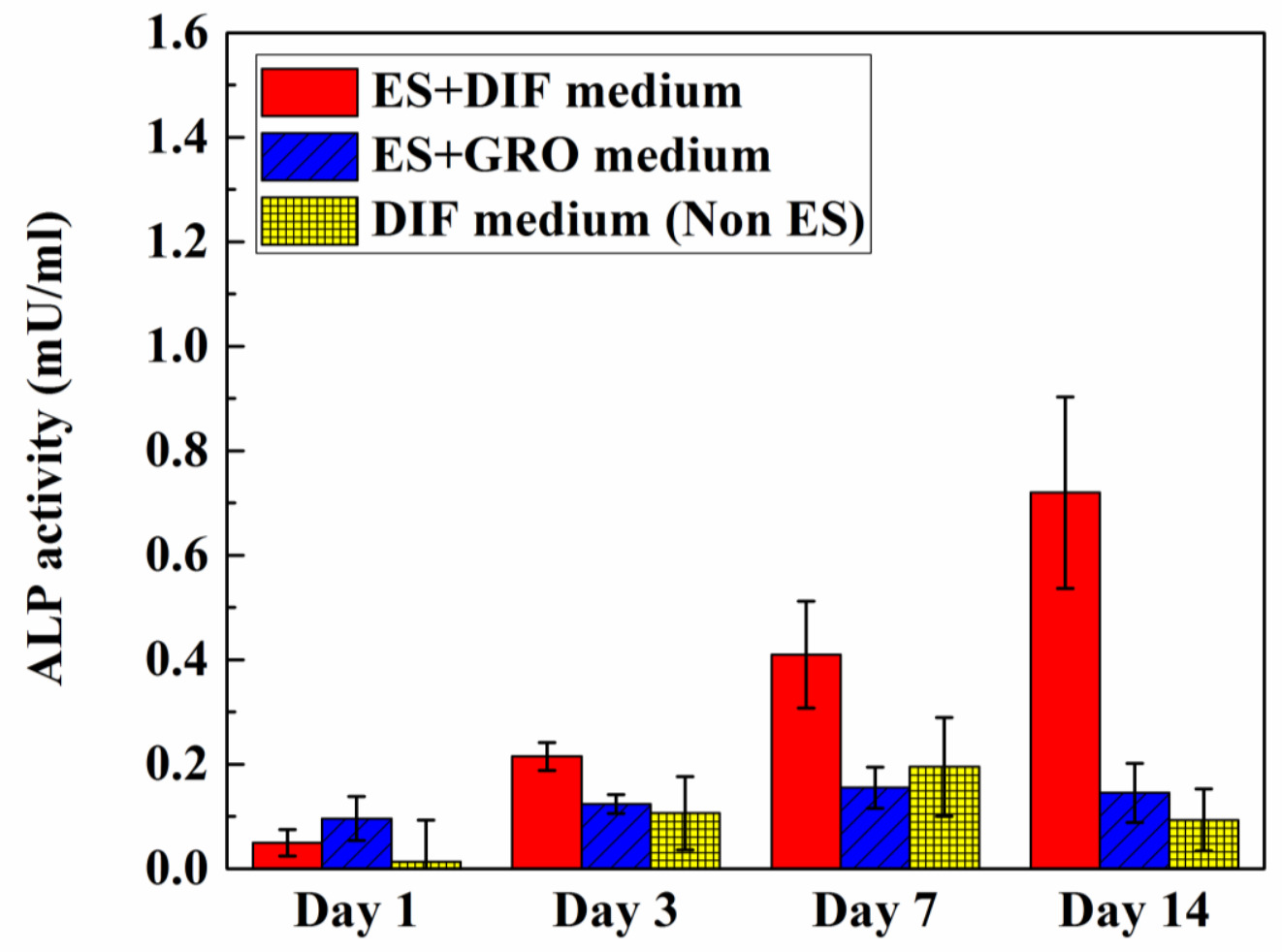

2 Fig. 9. Time course of ALP activity of ADSCs up to day 14 of ES and osteogenic 3 differentiation. Test samples were compared with ADSCs cultured in DIF medium or GRO 4 medium with ES or ADSCs cultured in DIF medium without ES. Mean \pm standard deviation, $5 \mathrm{n}=3, P<0.01$ (ES+DIF medium Day $14 v s$ all the comparisons; ES+DIF medium Day $7 v s$ 6 ES+DIF medium Day 1 and Day 3; Non ES DIF medium Day 1 vs Non ES DIF medium Day 7 7; ES+DIF medium Day 7 vs ES+DIF medium and Non ES DIF medium Day 7). 